
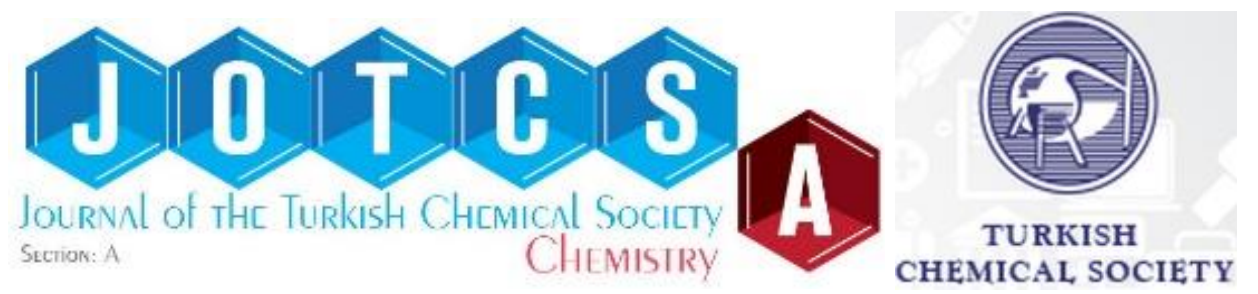

(This article was produced from $6^{\text {th }}$ National Congress of Inorganic Chemistry and was sent to the JOTCSA editorial board for publication)

\title{
CrVMO07: MICROWAVE SYNTHESIS AND STRUCTURAL CHARACTERIZATION
}

\author{
Gülşah Çelik Gül 1 \\ ${ }^{1}$ University of Balıkesir, 10145, Balıkesir, Turkey
}

Abstract: In this study, microwave synthesis method was operated to obtain $\mathrm{CrVMoO}_{7}$. Structural characterization of the compound was realized by powder X-ray diffraction (XRD) and Fourier transform infrared spectrometry (FTIR). Morphological property and elemental composition were determined via scanning electron microscopy (SEM) and energy dispersive X-ray analysis (EDS). Thermal nature of the sample was identified by thermogravimetric analyzer (TGA).

Keywords: $\mathrm{CrVMoO}_{7}$; X-ray diffraction; Rietveld refinement method; Microwave synthesis.

Submitted: May 22, 2017. Accepted: July 16, 2018.

Cite this: Çelik Gül G. CrVMoO7: MICROWAVE SYNTHESIS AND STRUCTURAL CHARACTERIZATION. JOTCSA. 2018;5(2):881-4.

DOI: http://dx.doi.org/10.18596/jotcsa.315212.

*Corresponding author. E-mail: gulsahcelik9@gmail.com, Tel.: +90 266612 1067/2012.

\section{INTRODUCTION}

Catalysis for most industrial processes has significance due to saving time, energy, and money. The catalysts used in these processes are generally transition metal oxides which are applied either alone or mixtures. The basic mixtures contain $\mathrm{V}_{2} \mathrm{O}_{5}$ and $\mathrm{MoO}_{3} / \mathrm{WO}_{3} / \mathrm{Fe}_{2} \mathrm{O}_{3} / \mathrm{Cr}_{2} \mathrm{O}_{3}$. Among them, $\mathrm{Cr}_{2} \mathrm{O}_{3}-$ $\mathrm{V}_{2} \mathrm{O}_{5}-\mathrm{MoO}_{3}$ three-component system has been studied in early times by many researchers (1-4). The formula $\mathrm{CrVMoO}_{7}$ as unknown phase has occurred by the reaction of $\mathrm{Cr}_{2} \mathrm{O}_{3}-\mathrm{V}_{2} \mathrm{O}_{5}-\mathrm{MoO}_{3}$ system in the solid-state form (5-7). The properties of this phase have been limitedly known, except melting point at $820^{\circ} \mathrm{C}$ to form solid $\mathrm{Cr}_{2} \mathrm{O}_{3}$ (2). According to the other investigations, the related phase has been formed via incorporation of $\mathrm{MoO}_{3}$ into the $\mathrm{Cr}_{2} \mathrm{~V}_{4} \mathrm{O}_{13}$ lattice $(6,7)$. It has not been examined in previous reports what the nature of $\mathrm{CrVMoO}_{7}$ is and how the structure occurs $(3,8,9)$. There are only a few documents about crystallographic morphology and thermal properties of $\mathrm{CrVMoO}_{7}$. The prominent one is about indexing of powder $X-$ ray diffraction pattern and calculation of unit cell parameters of $\mathrm{CrVMoO}_{7}$ resulting $a=5.53346 \AA$, $b=6.58901 \AA$ and $c=7.86551 \AA$ in triclinic system
(8). The infrared spectrum of the compound point out that $\mathrm{VO}_{4}, \mathrm{MoO}_{4}$ and $\mathrm{CrO}_{6}$ subgroups exist in the structure $(10,11)$. As a result of these, to the best of our knowledge, microwave synthesis, crystallographic, morphologic and thermal properties of $\mathrm{CrVMoO}_{7}$ have been studied for the first time with this paper which has not been reported previously.

\section{MATERIALS AND METHODS}

$\mathrm{Cr}_{2} \mathrm{O}_{3}, \mathrm{~V}_{2} \mathrm{O}_{5}$ and $\mathrm{MoO}_{3}$ compounds have been used as analytical grade and supplied by Merck. Oxide types starting materials have been weighed in $0.5: 0.5: 1$ molar ratio and ground in an agate mortar followed by microwave treatment in a domestic microwave oven $(2.45 \mathrm{GHz}, 850 \mathrm{~W}$ power) for $20 \mathrm{~min}$. The final sample has been washed three times with hot pure water and ethanol. The washed material has been treated at $400{ }^{\circ} \mathrm{C}$ for 2 hours to get the best crystals.

The powder X-ray diffraction (XRD) measurement has been completed by Panalytical $X^{\prime}$ Pert Pro Diffractometer and CuKa radiation $(\lambda=1.54056 \AA$, $40 \mathrm{~mA}, 50 \mathrm{kV}$ ) with a scan rate of $1 \% / \mathrm{min}$ with a step size $0.02^{\circ}$. The Rietveld analysis of the sample has been calculated by using powder 
diffraction data via High Score Plus (HS+) Program (License number: 92000029). Fourier transform infrared spectrum (FTIR) has been formed on a Perkin Elmer Spectrum 100 FTIR Spectrometer from 4000 to $650 \mathrm{~cm}^{-1}$. Scanning electron microscopy/energy dispersive X-ray analysis has been achieved in SEM JEOL 6390LV/EDX. Thermal property of the sample has been checked by Perkin Elmer thermogravimetric analyzer TGA. A Siemens V12 domestic microwave oven has been used as the microwave source.

\section{RESULTS AND DISCUSSION}

Figure 1 displays the XRD pattern of the synthesized material. The XRD pattern of the sample corresponds to $\mathrm{CrVMoO}_{7}$ with the ICSD card number 008-5712 (Fig. 2). The unit cell parameters of the observed diffraction data has been calculated by Rietveld Refinement Program. The findings are completely in accordance with database given in Table 1 . There is no other phase as an impurity or starting material.

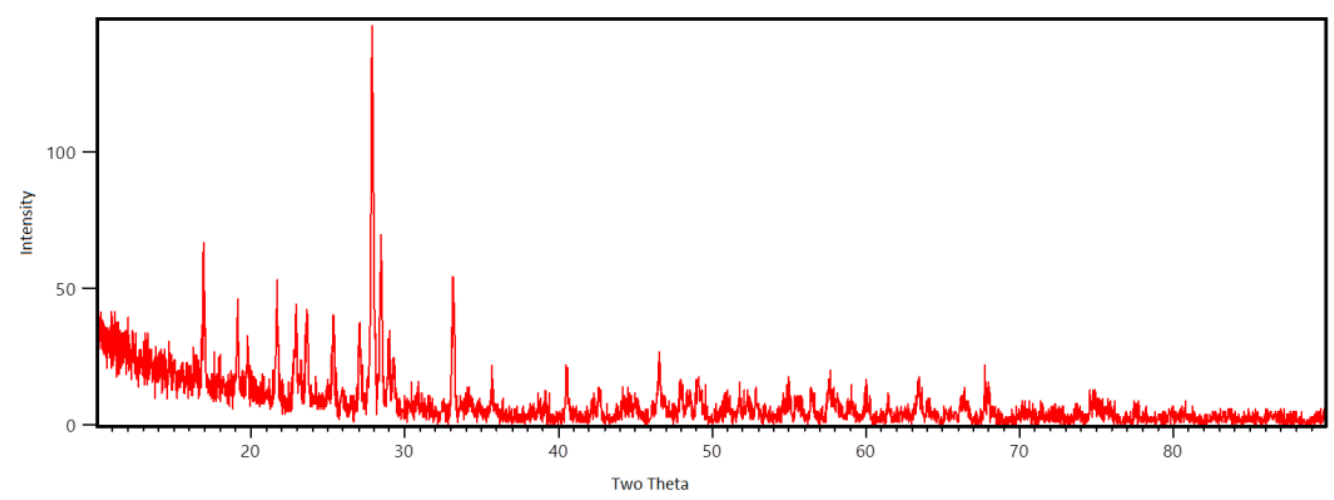

Figure 1. The XRD pattern of $\mathrm{CrVMoO}_{7}$.

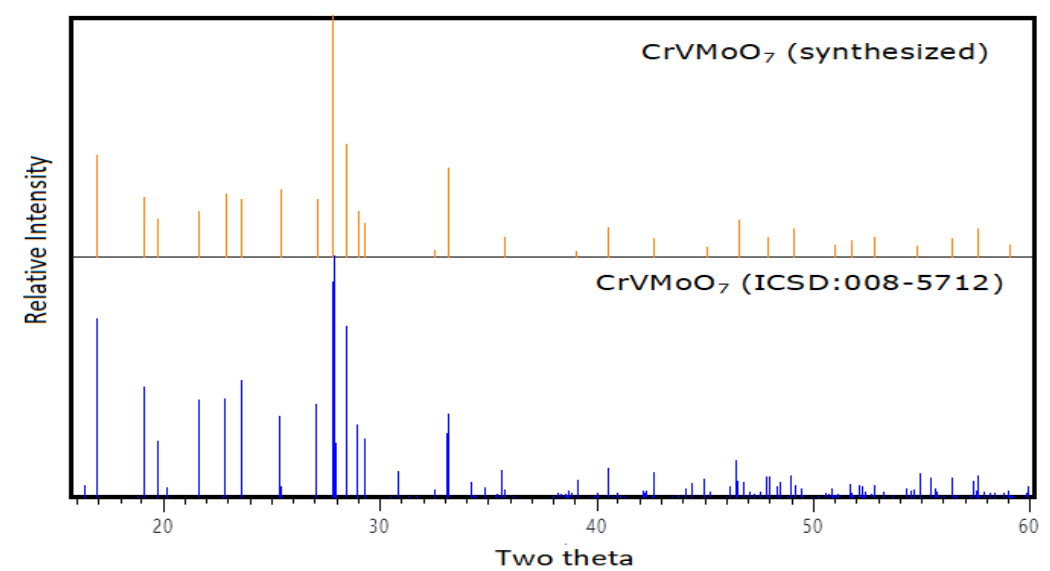

Figure 2. The comparison of powder XRD pattern between $\mathrm{CrVMoO}_{7}$ (ICSD:008-5712) and $\mathrm{CrVMoO}_{7}$ (synthesized).

Table 1. The comparison of unit cell parameters calculated and database values.

\begin{tabular}{lccc}
\hline Compound & \multicolumn{3}{c}{ Unit cell parameters } \\
& $\mathrm{a}(\AA)$ & $\mathrm{b}(\AA)$ & $\mathrm{c}(\AA)$ \\
\hline $\mathrm{CrVMoO}_{7}(\mathrm{ICSD}: 008-5712)$ & 5.5310 & 6.5850 & 7.8640 \\
$\mathrm{CrVMoO}_{7}$ (synthesized) & 5.5253 & 6.5792 & 7.8532 \\
\hline
\end{tabular}

Figure 3 shows FTIR spectrum of $\mathrm{CrVMoO}_{7}$. The four wavenumbers in the range of $600-1000 \mathrm{~cm}^{-}$
1 correspond to vibrations of $\mathrm{M}-\mathrm{M}$ and $\mathrm{Mo}-\mathrm{O}$ bonds $(12-14)$. 


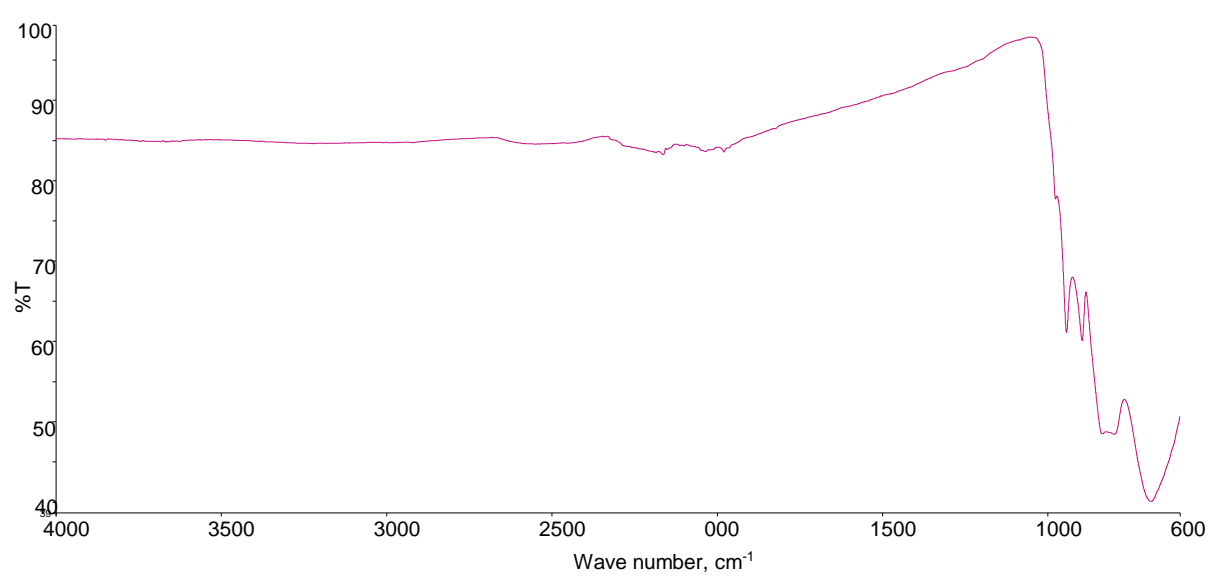

Figure 3. The FTIR spectrum of $\mathrm{CrVMoO}_{7}$.

Figure 4 exhibits the SEM micrograph of $\mathrm{CrVMoO}_{7}$. formation of chromium vanadium molybdate. The The homogeneous view of the sample confirm the particle size distribution of $\mathrm{CrVMoO}_{7}$ is in $2-5 \mu \mathrm{m}$.

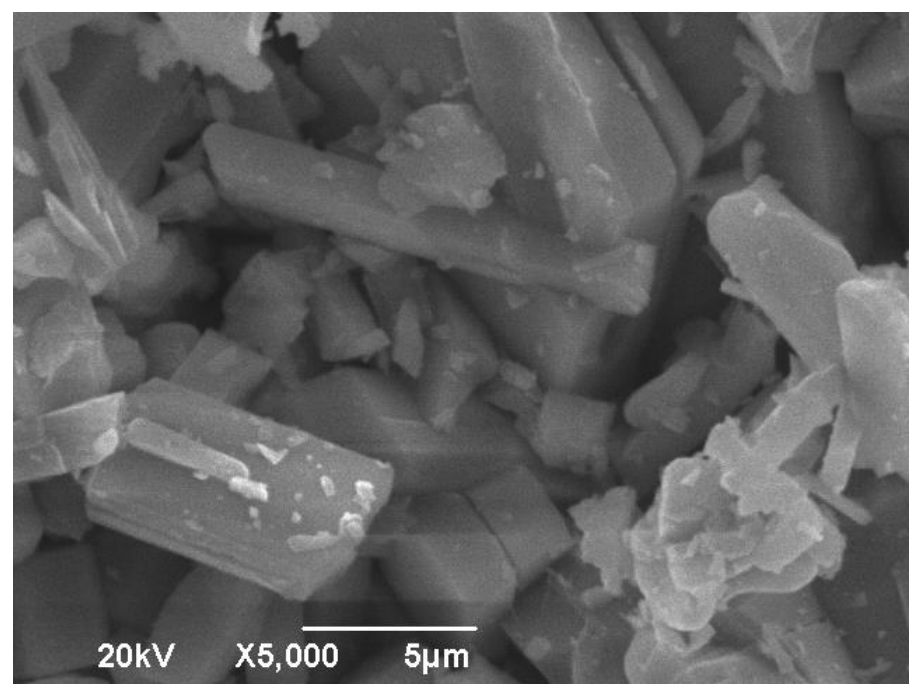

Figure 4. The SEM image of $\mathrm{CrVMoO}_{7}$.

The EDS graph of $\mathrm{CrVMoO}_{7}$ is given in Figure 5 . The elemental composition of the compounds has been calculated as $3: 3: 3.2: 6.8$ by EDS results which are in accordance with the molecular formula.

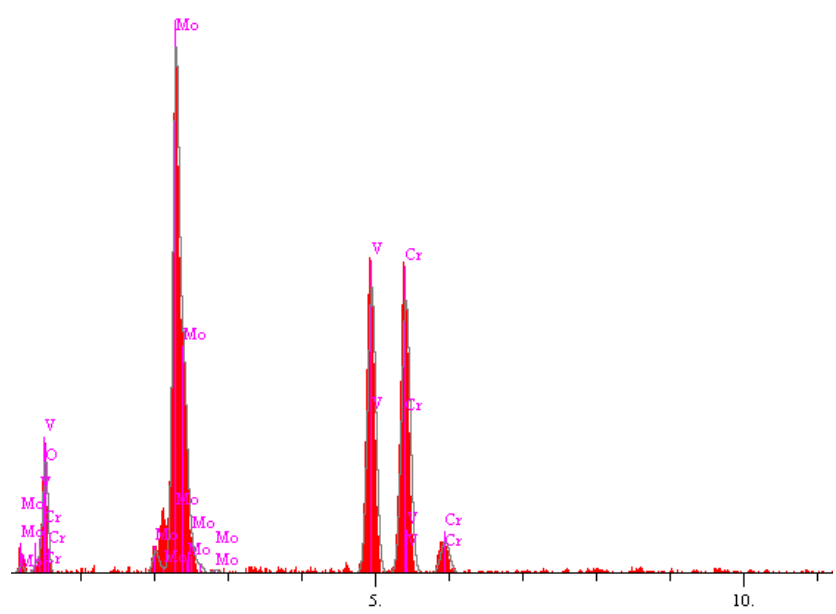

Figure 5. The EDS graph of $\mathrm{CrVMoO}_{7}$.

The graph of thermogravimetric analysis is represented in Figure 6 . The first smaller thermal loss starts nearly at $700{ }^{\circ} \mathrm{C}$, and the other is in the range of $1050-1200{ }^{\circ} \mathrm{C}$. The material lost totally $40 \%$ of its mass. 


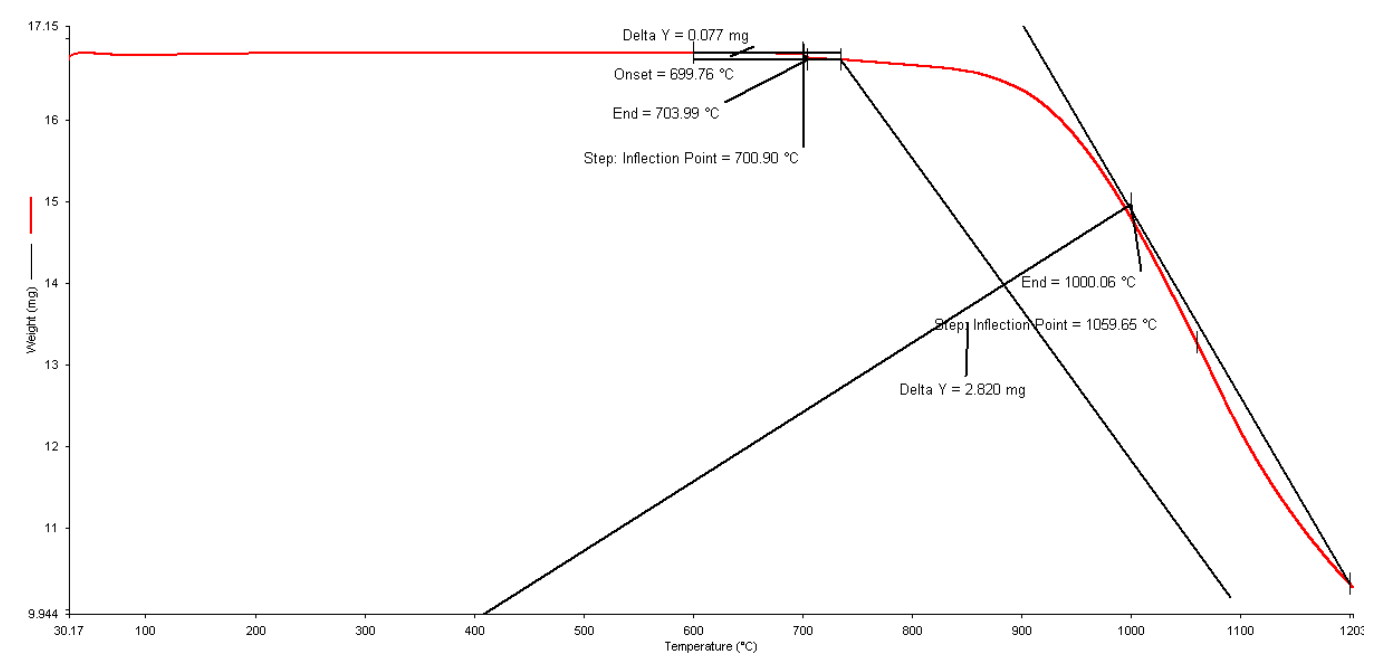

Figure 6. TGA thermograph of $\mathrm{CrVMoO}_{7}$.

As a conclusion, $\mathrm{CrVMoO}_{7}$ has been synthesized for the first time with microwave method at 850 $\mathrm{W}$ power for 20 minutes. The unit cell parameters of the compound have been calculated by Rietveld Refinement Program benefiting from XRD data. The homogeneous morphology and similar elemental composition have been confirmed via SEM and EDS results. High thermal stability of the compound has been determined from TGA.

\section{ACKNOWLEDGMENTS}

We want to thank The Scientific and Technological Research Council of Turkey and Scientific Research Project Fund of Balikesir University for financial supports and Dr. Sevim Demirözü Şenol for scientific support.

\section{REFERENCES}

1. Walczak J, Filipek E. In Sofia, Bulgaria: IUPAC; 1987. p. 171.

2. Walczak J, Filipek E. The CrVO4-MoO3 system. Thermochimica Acta. 1989 Sep;150(1):125-31.

3. Walczak J, Filipek E. Phase equilibria in the Cr2V4013-CrVMoO7 system. Thermochimica Acta. 1990 May;161(2):239-45.

4. Walczak J, Filipek E. Studies on the V2O5CrVMoO7 system. Thermochimica Acta. 1990 Dec;173:235-40.

5. Walczak J, Filipek E. Zeszyty Naukowe Politechniki Slaskiej. Seria: Chemia. 1988;119(958):380.
6. Walczak J, Filipek E. Reactivity of MoO3 towards Cr2V4O13. Thermochimica Acta. 1988 Oct; $133: 67-72$.

7. Kuriata J, Sadłowski L, Walczak J, Filipek E. Temperature Dependence of the EPR Linewidth of CrVO4. physica status solidi (b). $1987 \mathrm{Jul}$ $1 ; 142(1):$ K73-7.

8. Walczak J, Filipek E, Tabero P. CrVMoO7 and phase equilibria in the V9Mo6040-CrVMoO7 system. Thermochimica Acta. 1992 Sep;206:279-84.

9. Walczak J, Filipek E. Studies on the CrVMoO7Cr2(MoO4)3 system. Thermochimica Acta. 1993 Nov;228:127-30.

10. Walczak J, Rychiowska-Himmel I, Tabero P. Iron(III) tungstate and its modifications. Journal of Materials Science. 1992;27(13):3680-4.

11. Plasova L, Kefeli L. Inorganic Materials. Vol. 3. $1967.906 \mathrm{p}$.

12. Baykal A, Kizilyalli M, Kniep R. X-ray powder diffraction and IR study of $\mathrm{NaMg}(\mathrm{H} 2 \mathrm{O}) 2$ [BP2O8] $\mathrm{H} 2 \mathrm{O}$ and $\mathrm{NH} 4 \mathrm{Mg}$ (H2O) 2 [BP2O8]. $\mathrm{H} 2 \mathrm{O}$. Journal of materials science. 2000;35(18):4621-4626.

13. Gözel G, Kizilyalli M, Kniep R. Characterization of a new calcium ultraphosphate, Ca3 (P5O14) 2. Journal of Solid State Chemistry. 1997;129(2):196-199.

14. Gözel G, Baykal A, Kizilyalli M, Kniep R. Solid-State Synthesis, X-ray Powder Investigation and IR Study of a-Mg3[BPO7]. Journal of the European Ceramic Society. 1998 Dec;18(14):2241-6. 